\title{
Efficacy of Fluralaner (Exzolt@) for the Treatment of Natural Allopsoroptoides Galli Infestations in Laying Hens
}

Nilce Maria Soares

Instituto Biologico

Edna Clara Tucci

Instituto Biologico

Gustavo Perdoncini ( $\nabla$ gustavo.perdoncini@yahoo.com )

MSD: Merck \& Co Inc https://orcid.org/0000-0002-3249-5701

Ricardo Della Matta Junior

MSD: Merck \& Co Inc

Research

Keywords: Ectoparasite, Mites, Stress, Acaricide, Fluralaner

Posted Date: December 29th, 2021

DOI: https://doi.org/10.21203/rs.3.rs-1181968/v1

License: (c) (i) This work is licensed under a Creative Commons Attribution 4.0 International License.

Read Full License 


\section{Abstract}

\section{Background}

Mite infestations in laying hens can cause losses to producers due to stress, reduced egg production and even death of birds. A new species of mite, Allopsoroptoides galli (A. galli), Analgoidea: Psoroptoididae, was recently identified in commercial laying farms in Brazil, causing damage due to its highly aggressive infestation that results in a sharp drop in egg production and culling. The present study evaluated the acaricidal action of a formulation containing fluralaner (Exzolt ${ }^{\circledR}$ ) against $A$. galli.

Methods

The study was carried out from November 2019 to January 2020. Thirty-four laying hens naturally infested with $A$. galli were equally divided into a fluralaner-treated group and an untreated control group. The fluralaner-treated group received Exzolt ${ }^{\circledR}$ in drinking water at a dose of $0.05 \mathrm{~mL} / \mathrm{kg}$ body weight (equivalent to $0.5 \mathrm{mg}$ fluralaner/ $\mathrm{kg}$ body weight), twice, seven days apart. Both groups were followed for 70 days evaluating the level of infestation by counting mites in skin scrapings and assessment of skin lesions.

Results

The average mite count of the treated group decreased significantly, dropping from 61.6 to 3.8 mites ( $D+7$ to $\mathrm{D}+70$ ). The efficacy progressively increased on subsequent days, reaching $98.8 \%$ on day +56 posttreatment and $96.9 \%$ on day +70 . Recovery of skin lesions was observed after administration of Exzolt ${ }^{\circledR}$, showing a marked remission in the degree of lesions ( 2.5 on day -14 to 0.2 on day +70$)$. The mean number of mites in the untreated control group ranged from 79.3 to 124.1 and the lesion score from 2.6 to 2.9 , thus remaining stable throughout the study.

Conclusion

The results obtained in the present study demonstrated that Exzolt ${ }^{\circledR}$ administered at a dose of $0.05 \mathrm{~mL}$ of product $/ \mathrm{kg}$ body weight (equivalent to $0.5 \mathrm{mg}$ of fluralaner $/ \mathrm{kg}$ body weight), twice at a seven-day interval, in drinking water was effective in the treatment of the mite Allopsoroptoides galli in naturally infested laying hens.

\section{Background}

The proliferation of ectoparasites has caused significant economic losses in confined poultry production, where these parasites find ideal conditions for infestation. These ectoparasites feed on the animal's blood, lymph, damaged skin, or sebaceous secretions [1]. The presence of arthropod parasites in a flock of chickens increases the production costs and contributes to spreading of avian diseases due to 
weakness, stress, anemia, and weight loss in chickens. Signs of an infestation include a decrease in egg production without reduced feed intake, leading to a reduction in the feed conversion ratio $[2,3,4]$.

Allopsoroptoides galli (A. galli; Analgoidea: Psoroptoididae), a new mite species, has been found with increasing frequency in commercial farms in Brazil[5]. According to the author of the new genus and species [5], this is the first record of feather mites of the Psoroptoididae family parasitizing on Galliformes, which aroused the interest of acarologists on the origin of the mite in the wild. Hernandes et al. (2014) [6] identified the wild bird Guira cuckoo (Guira; Cuculiformes: Cuculidae), as the reservoir host of $A$. galli. Generally, feather mites have specific hosts [7].

However, intensively reared chickens provide ideal conditions for $A$. galli. This new parasite is aggressive to chickens, causing severe discomfort with hyperactivity of the birds, which spend considerable time and energy scratching themselves and trying to remove the mites with their beaks. Fifteen days after the initial infestation, the birds present intense itching and severe dermatitis, which are the main clinical manifestations. Currently, little is known about this parasite's biology, ecology, and control [8].

Soares et al. (2016) [9] investigated the economic losses caused by A. galli, comparing the performance of artificially infested chickens with an un-infested control group. Although feed intake did not differ between the two groups, final body weight, egg production, feed conversion, and egg weight were significantly lower in infested hens; egg production was reduced by $31 \%$ in the infested group.

It is believed that $A$. galli had no previous contact with acaricidal substances until their arrival in poultry production houses and that this species is therefore sensitive to the commercially available acaricides. This has been verified by some authors $[10,11,12]$ in tests with botanical acaricides and older chemical products. While these products showed acaricidal action on A. galli, they are associated with the inconvenience of being applied via spraying, bathing, and powdering, which causes additional stress to the birds and can result in insufficient efficacy if not applied thoroughly.

A new formulation of an insecticide and acaricide drug containing fluralaner [Exzolt $\circledast$; 13], which is administered in the poultry's drinking water, effectively treated infestations with poultry red mites (Dermanyssus gallinae) and northern fowl mites (Ornithonyssus sylviarum) in hens [14, 15]. Fluralaner, an isoxazoline compound for use as a systemic treatment, kills mites by binding to a distinct, previously unrecognized receptor site on $Y$-aminobutyric acid (GABA) and L-glutamate-gated chloride channels, which are widely expressed in the central nervous and peripheral neuromuscular systems in insects and acari $[16,17]$. Exzolt ${ }^{\circledR}$ is registered in Brazil for the treatment of $D$. gallinae and 0 . sy/viarum in chickens which provided the basis for evaluating the efficacy against $A$. galli when administered at the same dose. In addition, the systemic administration of fluralaner via the bird's drinking water is a convenient, safe [18, $20,24]$ and efficient method for controlling ectoparasites.

The control of mites, especially A. galli, in egg production farms is essential to minimize the discomfort of birds and losses to the producer. Thus, the present study aimed to evaluate the acaricidal efficacy of 
fluralaner (Exzolt $\circledast)[13,18]$, which has successfully been used in the treatment and control of hematophagous mites in commercial laying poultry $[14,19,21]$ when administered in the drinking water.

\section{Materials And Methods}

The study was conducted in Bastos (a city in São Paulo state; S $21^{\circ} 56^{\prime} 15^{\prime \prime}$; W 50 $40^{\circ} 41^{\prime} 15^{\prime \prime}$ ), using an experimental shed belonging to the Bastos Research and Development Unit/Institute of Biology SP/Brazil. The study was carried out between November 2019 and January 2020. The Ethics Committee previously approved the procedures for Animal Experiments (CETEA/IB) under Protocol No. 165/19.

For the study, a total of 34 white hens, Dekalb breed, 56 weeks of age, were purchased from a commercial hen farm in the city of Bastos-SP, where $A$. galli infestations had previously been identified and the animals presented mite-induced skin lesions. The birds were housed in a closed shed, equipped with galvanized wire cages, trough-type feeders, and drinking bowls. The birds received feed and water ad libitum and were subjected to a lighting program with $16 \mathrm{~h}$ of daily light.

Thirty-four hens naturally infested with $A$. galli mites were included in this blinded and randomized trial. The animals were distributed homogeneously between the experimental groups by their mean mite count on day -1. Each hen represented an experimental unit. The study consisted of two experimental groups of 17 hens each: the treated group received the fluralaner formulation (Exzolt ${ }^{\circledR}$ ) in drinking water at a dose of $0.05 \mathrm{~mL} / \mathrm{kg}$ body weight, twice, 7 days apart (day 0 and day 7 ); the control group received no treatment.

The efficacy evaluations were carried out by mite counts and quantification of skin lesions. Evaluations were performed on all hens before treatment (day -1) and post-treatment on days 7, 14, 21, 28, 42, 56, and 70, according to the procedure described by Tucci et al. (2019) [18]:

Mites were counted by skin scrapings: On each evaluation day, three skin areas of at least $1 \mathrm{~cm}^{2}$ were scraped for each animal - wings, flank, and back. The skin scraping was deposited on a microscope glass slide, mixed with a drop of $0.1 \mathrm{M}$ sodium hydroxide solution and protected with a coverslip. Using a $10 \mathrm{X}$ magnification microscope, the field was focused on the top corner of the coverslip and the slide was assessed systemically, counting any adult mites.

Tucci et al. (2019) [22] measured the skin lesions caused by A. galli infestation based on the degree of dermatitis. The animals' wings, sides, and backs were examined and classified as follows: 0 - no dermatitis; 1 - mild dermatitis; 2 - moderate dermatitis; 3 - median dermatitis; 4 - severe dermatitis; and 5 - very severe dermatitis. For skin lesions efficacy, a mean of these degrees was calculated considering wings, sides, and backs.

Statistical analysis of infestation data for both groups was performed using the Student's t-test, considering the probability level of $5 \%$. To evaluate the efficacy against the mite, the following Abbott 
formula (1987) [23] was used: Efficacy $(\%)=100 \times(\mathrm{mc}-\mathrm{tm}) / \mathrm{mc}$; (mc: mean of live mites in control animals before treatment and tm: mean of live mites in treated animals after treatment).

\section{Results}

The results are shown in Tables 1 and 2 and Figures 1 to 4.

\section{Skin scrapings}

In the fluralaner-treated group, the mite count assessed by skin scraping showed a significant decrease $(p<0.005)$ from the first day of evaluation (day 7$)$ after the first dose of Exzolt $\circledast$ (Table 1, Figures 1 and 2). The mite population continued to decline thereafter. On day 14 , the reduction reached $59.2 \%$ and exceeded $80 \%$ from day $21(80.7 \%)$ onwards with values of $94.8 \%$ on day 28 and $98.3 \%$ on day 44 . The maximum efficacy value was seen on day 56 with $98.8 \%$. The number of mites in the control group remained high throughout the study.

Table 1

The mean number of $A$. galli mites found in skin scrapings on different evaluation days.

\begin{tabular}{|lllllllll|}
\hline & \multicolumn{7}{|c|}{ Evaluation day } \\
\cline { 2 - 9 } & D-14 & D+7 & D+14 & D+21 & D+28 & D+44 & D+56 & D+70 \\
\hline Exzolt@ & $78.4 \mathrm{a}$ & $61.6 \mathrm{a}$ & $41.6 \mathrm{a}$ & $16.3 \mathrm{a}$ & $4.3 \mathrm{a}$ & $1.8 \mathrm{a}$ & $1.4 \mathrm{a}$ & $3.8 \mathrm{a}$ \\
\hline Control & $79.3 \mathrm{a}$ & $91.5 \mathrm{~b}$ & $101.9 \mathrm{~b}$ & $84.6 \mathrm{~b}$ & $82.4 \mathrm{~b}$ & $103.5 \mathrm{~b}$ & $112.1 \mathrm{~b}$ & $124.1 \mathrm{~b}$ \\
\hline Efficacy (\%) & - & 32.7 & 59.2 & 80.7 & 94.8 & 98.3 & 98.8 & 96.9 \\
\hline $\begin{array}{l}\text { Means followed by the same letter do not differ from each other at the 5\% significance level } \\
\text { (Student's t-test) }\end{array}$
\end{tabular}

\section{Skin lesions}

A statistical difference $(\mathrm{p}<0.005)$ between the treated and control group in skin lesions caused by $A$. galli was observed from day 7 (Table 2, Figures 3 and 4) onwards characterized by remission of lesions and consequently a decrease in the degree of dermatitis in the treated group. Table 2 shows the results obtained throughout the study, where efficacy values above $80 \%$ can be noticed on day $44(85.2 \%)$ and day $56(85.7 \%)$. The highest value was seen on day 70 with $93.1 \%$ efficacy in improvement of lesions. These results demonstrate that the recovery of birds' lesions caused by the mite parasitism takes longer than the acaricide effect of the product. 
Table 2

Mean degree of dermatitis in laying hens caused by A. galli on different evaluation days.

\section{Evaluation day}

\begin{tabular}{|lcccccccc|} 
& D-14 & D7 & D14 & D21 & D28 & D44 & D56 & D70 \\
\hline Exzolt@ & $2.5 \mathrm{a}$ & $2.1 \mathrm{a}$ & $1.6 \mathrm{a}$ & $1.3 \mathrm{a}$ & $1.0 \mathrm{a}$ & $0.4 \mathrm{a}$ & $0.4 \mathrm{a}$ & $0.2 \mathrm{a}$ \\
\hline Control & $2.6 \mathrm{a}$ & $2.7 \mathrm{~b}$ & $2.6 \mathrm{~b}$ & $2.5 \mathrm{~b}$ & $2.6 \mathrm{~b}$ & $2.7 \mathrm{~b}$ & $2.7 \mathrm{~b}$ & $2.9 \mathrm{~b}$ \\
\hline Efficacy (\%) & - & 22.2 & 38.5 & 48.0 & 61.5 & 85.2 & 85.7 & 93.1 \\
\hline $\begin{array}{l}\text { Means followed by the same letter do not differ from each other at the 5\% significance level } \\
\text { (Student's t-test) }\end{array}$
\end{tabular}

The results show that Exzolt $\circledast$ has an acaricidal action on $A$. galli resulting in an improvement in clinical signs of parasitism throughout the trial period. Assessing the skin lesion score is essential for following the birds' clinical evolution.

\section{Discussion}

Ectoparasite control is an essential part of management in the egg production industry to control the damage caused to birds and the losses caused to producers. Among the ectoparasites, mites belong to the most important group, causing significant losses to the poultry industry. Despite the importance of these arthropods, there are few compounds with an indication for use and registered with competent agencies for laying poultry. With only few molecules available, it is challenging to design control programs aimed at a broader and more extended use of active pharmaceutical ingredients and to implement the molecule rotation technique aiming to manage resistance development. Fluralaner is a molecule that was recently introduced in the market (Exzolt $\left.{ }^{\circledR}\right)$ and has since been used with great success in the treatment and control of hematophagous mites in commercial laying farms $[13,14,18,19$, 21]. The efficacy of Exzolt $\circledast$ against infestations with poultry red mites (D. gallinae) and Northern fowl mites (O. sy/viarum) has already been reported $[14,19,21]$.

In this study, Exzolt ${ }^{\circledR}$ showed acaricidal efficacy in the treatment and control of the mite A. galli and it effectively reduced mite-induced dermatitis. Similar results to this study were obtained by Hinkle et al. (2018) [14] in the treatment and control of $O$. sylviarum, where fluralaner showed efficacy above $90 \%$ after three weeks from the initial treatment. A study with strains of $D$. gallinae from Europe and Brazil showed that mites are susceptible to fluralaner but resistant to other molecules tested by the authors [15]. During field studies with laying hens, fluralaner effectively controlled $D$. gallinae, showing efficacy above $90 \%$ for up to 8 months after the initial treatment [19] if re-infestation with new mites is strictly prevented by biosecurity measures on the farm. 
No adverse effects were seen throughout this study consistent with a study conducted by Prohaczik et al. (2017) [24] which assessed the safety of fluralaner in laying hens by analyzing clinical and laboratory parameters, including egg production and egg quality. The authors have found that the oral administration of fluralaner via drinking water at the recommended treatment dose $(0.5 \mathrm{mg} / \mathrm{kg}$ body weight, twice at a 7-day interval) was safe for the birds and did not impact egg production or egg quality. A similar study was carried out by Huyghe et al. (2017) [18], which confirmed the safety of fluralaner in breeder chickens, noting that fluralaner did not affect the number of eggs, egg weight, or fertility of birds, nor the hatchability of chicks or chick viability. Furthermore, a field study in Europe showed a significant improvement on animal welfare when treating mite-infested chickens with Exzolt $\circledast$ [25].

For an efficient treatment of mite infestations in chickens, in addition to being effective and safe, the compound must be easy to apply. One of fluralaner's significant advantages is the convenient administration via drinking water that is well accepted by producers. It considerably reduces the time needed to treat birds (thousands of birds can be treated in a single period of the day) and eliminates the need for additional equipment or labor. Another essential factor is the immense stress suffered by birds during treatment when using methods such as bathing or spraying, which is eliminated by using the fluralaner product.

\section{Conclusion}

The results obtained in this study showed that Exzolt ${ }^{\circledR}$ (fluralaner) at a dose of $0.05 \mathrm{~mL}$ of product per $\mathrm{kg}$ of body weight (equivalent to $0.5 \mathrm{mg}$ of fluralaner per $\mathrm{kg}$ of body weight) administered twice, seven days apart, in the drinking water was effective in the treatment and control of the mite Allopsoroptoides galli and reducing mite-induced skin lesions in naturally infested laying hens.

\section{Declarations}

\section{Ethical approval and consent to participant}

The Ethics Committee previously approved the procedures for Animal Experiments (CETEA/IB) under Protocol No. 165/19.

\section{Consent for publication}

Not applicable.

\section{Competing interests}

The authors declare no conflicting interests

\section{Funding}

The study was funded by MSD Animal health with OSTIC approval ID: 2021-ms-5447. 


\section{Authors' contributions}

NMS, ECT, GP and RDMJ conceived and designed the experiments. NMS, GP and RDMJ performed the experiments. NMS and ECT analyzed the data. NMS, ECT, GP and RDMJ wrote and revised the manuscript. All authors read and approved the final manuscript.

Acknowledgements: The authors would like to thank the employees from Biological Institute for monitoring the study and the employees from MSD Animal Health for their valuable comments and suggestions with the manuscript.

\section{Availability of data and material}

The data generated or analyzed during these studies are included partially in this published article. They are the property of the sponsor and will not be further provided.

\section{References}

1. DeVaney JA. A survey of poultry ectoparasite problems and their research in the United States. Poult Sci. 1978;57:1217-20.

2. Tucci EC, Soares NM, Alves LFA, André MR, Potenza MR. Ectoparasitas e pragas associadas à avicultura industrial. In: Andreatti Filho RL, Berchieri Júnior A, Silva EN, Back A, Di Fabio J, Zuanase MAF, editores. Doença das Aves. 3. ed. Campinas: Fundação APINCO; 2020. p. 1049-1080.

3. Arends JJ. External Parasites and Poultry Pets. Calnek BW. Diseases of Poultry. 9th ed. Ames: lowa State University Press; 1991. pp. 702-30.

4. Hinkle NC, Hickle L. External Parasites and Poultry Pets. Sayf YM. Diseases of poultry. 12th ed. Ames: lowa State University Press; 2008. pp. 1011-24.

5. Mironov SV. Allopsoroptoides galli n.g., n.sp., a new genus and species of feather mites (Acari:Analgoidea: Psoroptoididae) causing mange in commercially raised domestic chicken in Brazil. Syst Parasitol. 2013;85(3):201-12.

6. Hernandes FA, Pedroso LGA, Mironov SV. From cuckoos to chickens: a caught-in-the-act case of host shift in feather mites (Arachnida: Acari: Psoroptoididae). Parasitol Res. 2014;113:4355-61. doi:10.1007/s00436-014-4110-7.

7. Proctor HC. Feather mites (Acari: Astigmata): ecology, behavior, and evolution. Annu Rev Entomol. 2003;48:185-209.

8. Tucci EC, Soares NM, Faccini JLH, Vilas Boas D. Additional information about a mange outbreak by Allopsoroptoides galli (Acari: Psoroptoididae) in commercial laying hens in the state of São Paulo, Brazil. Pesq Vet Bras [Internet]. 2014 [cited 2021 Fev 02];34(8):760-2. Available from: https://www.scielo.br/pdf/pvb/v34n8/09.pdf doi: 10.1590/S0100-736X2014000800009.

9. Soares NM, Tucci EC, Freitas ER, Fernandes DPB. Reduced productivity among confined laying hens infested by Allopsoroptoides galli (Mironov, 2013). Poult Sci. 2016;95(4):819-22. 
doi:10.3382/ps/pev442.

10. Tucci EC, Soares NM. Acaricide effects of abamectin and ivermectin against Allopsoroptoides galli Mironov (Pandalurinae:Psoroptoididae) mite that causing dermatites in laying hens. In: Anais do IV SIBAC Simpósio Brasileiro de Acarologia [Internet]; 2013 Abr 30 - Mai 3; Bento Gonçalves, Rio Grande do Sul, BRA. Campinas: Infobibos; 2013 [cited 2021 Fev 2]. Available from: http://www.infobibos.com/anais/sibac/4/Resumos/ResumoSibac4_213.pdf.

11. Tucci EC, Soares NM, Ono MA, Vieira MR. The acaricidal effect of the botanical compound against Allopsoroptoides galli Mironov (Pandalurinae:Psoroptoididae) in laying hens. In: Anais do IV SIBAC Simpósio Brasileiro de Acarologia [Internet]; 2013 Abr 30 - Mai 3; Bento Gonçalves, Rio Grande do Sul, BRA. Campinas: Infobibos; 2013 [cited 2021 Fev 2]. Available from: .

12. Soares NM, Tucci EC. The bolfo action on controlling dermatites caused by mite in laying hens. In: Anais of the XXIV World's Poultry Congress; 2012 Ago 5-9; Salvador, BRA. Beekbergen:WPSA; 2012.

13. Gassel M, Wolf $\mathrm{C}$, Noack $\mathrm{S}$, Williams $\mathrm{H}$, Ilg T. The novel isoxazoline ectoparasiticide fluralaner: selective inhibition of arthropod $y$-aminobutyric acid- and L-glutamate-gated chloride channels and insecticidal/acaricidal activity. Insect Biochem Mol Biol. 2014;45:111-24. doi:10.1016/j.ibmb.2013.11.009.

14. Hinkle NC, Jirjis F, Szewczyk E, Sun F, Flochlay-Sigognault A. Efficacy and safety assessment of a water-soluble formulation of fluralaner for treatment of natural Ornithonyssus sy/viarum infestations in laying hens. Parasites Vectors. 2018;11:99. doi:10.1186/s13071-018-2678-y.

15. Thomas E, Zoller H, Liebisch G, Alves LFA, Vettorato L, Chiummo RM, Flochlay AS. In vitro activity of fluralaner and commonly used acaricides against Dermanyssus gallinae isolates from Europe and Brazil. Parasit Vectors. 2018;11:361.

16. Ozoe Y, Asahi M, Ozoe F, Nakahira K, Mita T. The antiparasitic isoxazoline A1443 is a potent blocker of insect ligand-gated chloride channels. Biochem Biophys Res Commun. 2010;391:744-9.

17. Casida JE. Golden age of RyR and GABA-R diamide and isoxazoline insecticides: common genesis, serendipity, surprises, selectivity, and safety. Chem Res Toxicol. 2015;28:560-6.

18. Huyghe B, Le Traon G, Flochlay-Sigognault A. Safety of fluralaner oral solution, a novel systemic poultry red mite treatment, for chicken breeders' reproductive performances. Parasit Vectors. 2017;31(1):10. doi:10.1186/s13071-017-2480-2. 540.

19. Thomas E, Chiquet M, Sander B, Zschiesche E, Flochlay AS. Field efficacy and safety of fluralaner solution for administration in drinking water for the treatment of poultry red mite (Dermanyssus gallinae) infestations in commercial flocks in Europe. Parasit Vectors. 2017;9(1):10. doi:10.1186/s13071-017-2390-3. 457.

20. European Medicines Agency. European public MRL assessment report (EPMAR) Fluralaner (poultry). Available at: http://www.ema.europa.eu/docs/ en_GB/document_library/Maximum_Residue_Limits__Report/2017/02/ WC500221753.pdf. Accessed Sept 2017.

21. Mullens BA, Murillo AC, Zoller H, Heckeroth AR, Jirjis F, Flochlay-Sigognault A. Comparative in vitro evaluation of contact activity of fluralaner, spinosad, phoxim, propoxur, permethrin and deltamethrin 
against the northern fowl mite, Ornithonyssus sylviarum. Parasites Vectors. 2017;10:358. doi:10.1186/s13071-017-2289-z.

22. Tucci EC, Soares NM, Sampaio PHS. Methodology for the assessment of parasitic infections caused by Allopsoroptoides galli (Acari, Psoroptoididae) in laying hens. In: Abstract Book of the 27th Conference of the World Association for the Advancement of Parasitology Conference (WAAVP 2019); 2019 Jul 7-11; Madison, Wisconsin, USA. Madison: WAAVP; 2019. v. 1, p. 119-120.

23. Abbot WS. A method of computing the effectiveness of an insecticide. J Am Mosq Control Assoc. 1987;3(2):302-3.

24. Prohaczik A, Menge M, Huyghe B, et al. Safety of fluralaner oral solution, a novel systemic antiparasitic treatment for chickens, in laying hens after oral administration via drinking water. Parasites Vectors. 2017;10:363. https://doi.org/10.1186/s13071-017-2291-5.

25. European Commission. Community register of veterinary medicinal products, Product information, Annex 1 Summary of product characteristics, Exzolt $10 \mathrm{mg} / \mathrm{ml}$ solution for use in drinking water for chickens. 2021. https://www.ema.europa.eu/en/documents/product-information/exzolt-eparproduct-information_en.pdf.

\section{Figures}

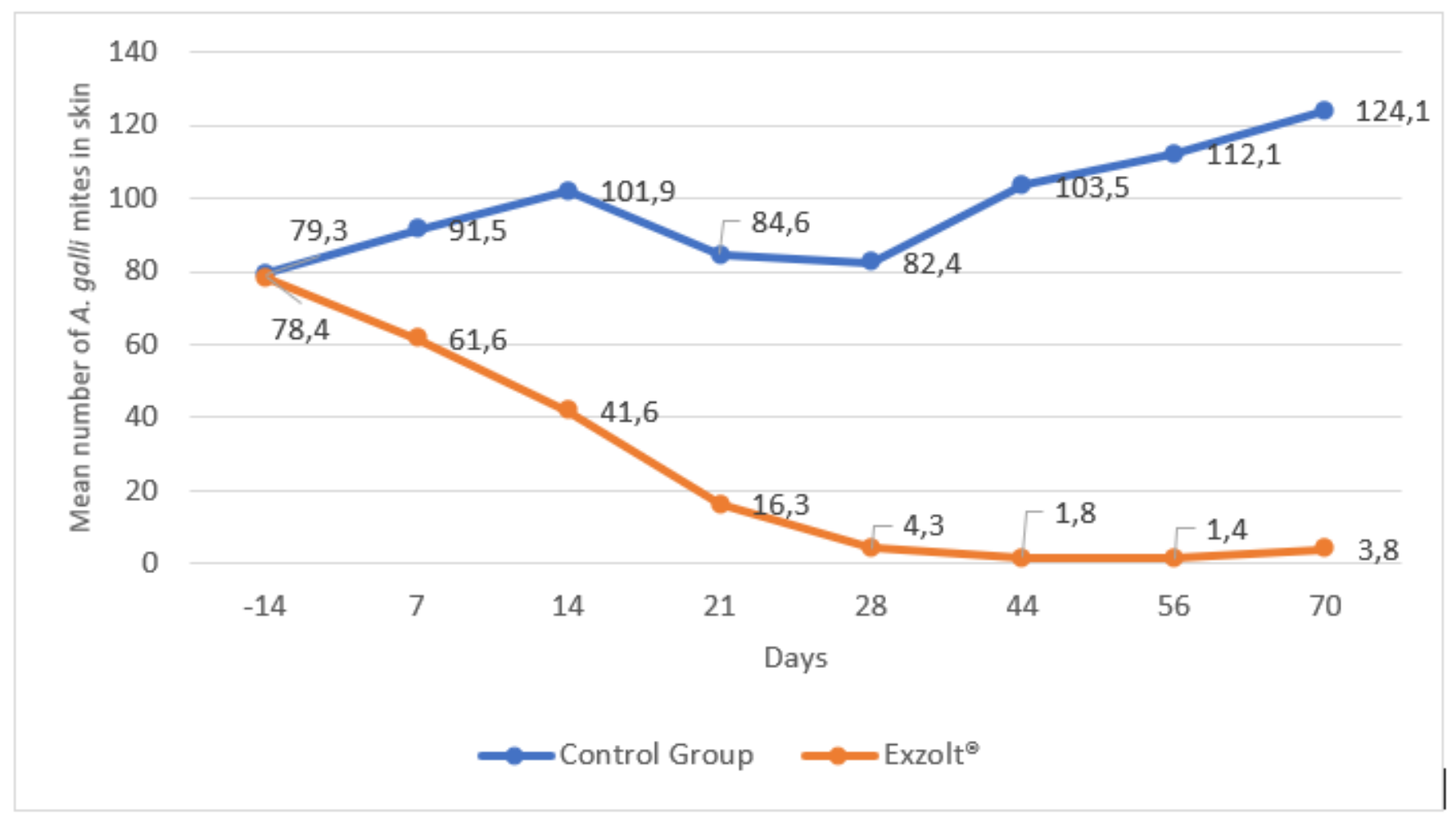

Figure 1. Mean number of $A$. galli mites in skin scrapings from chickens treated with Exzolt ${ }^{\circledR}$ on day 0 and day +7 and untreated chickens (control group) on different evaluation days. 
Figure 1

Mean number of $A$. galli mites in skin scrapings from chickens treated with Exzolt ${ }^{\circledR}$ on day 0 and day +7 and untreated chickens (control group) on different evaluation days.

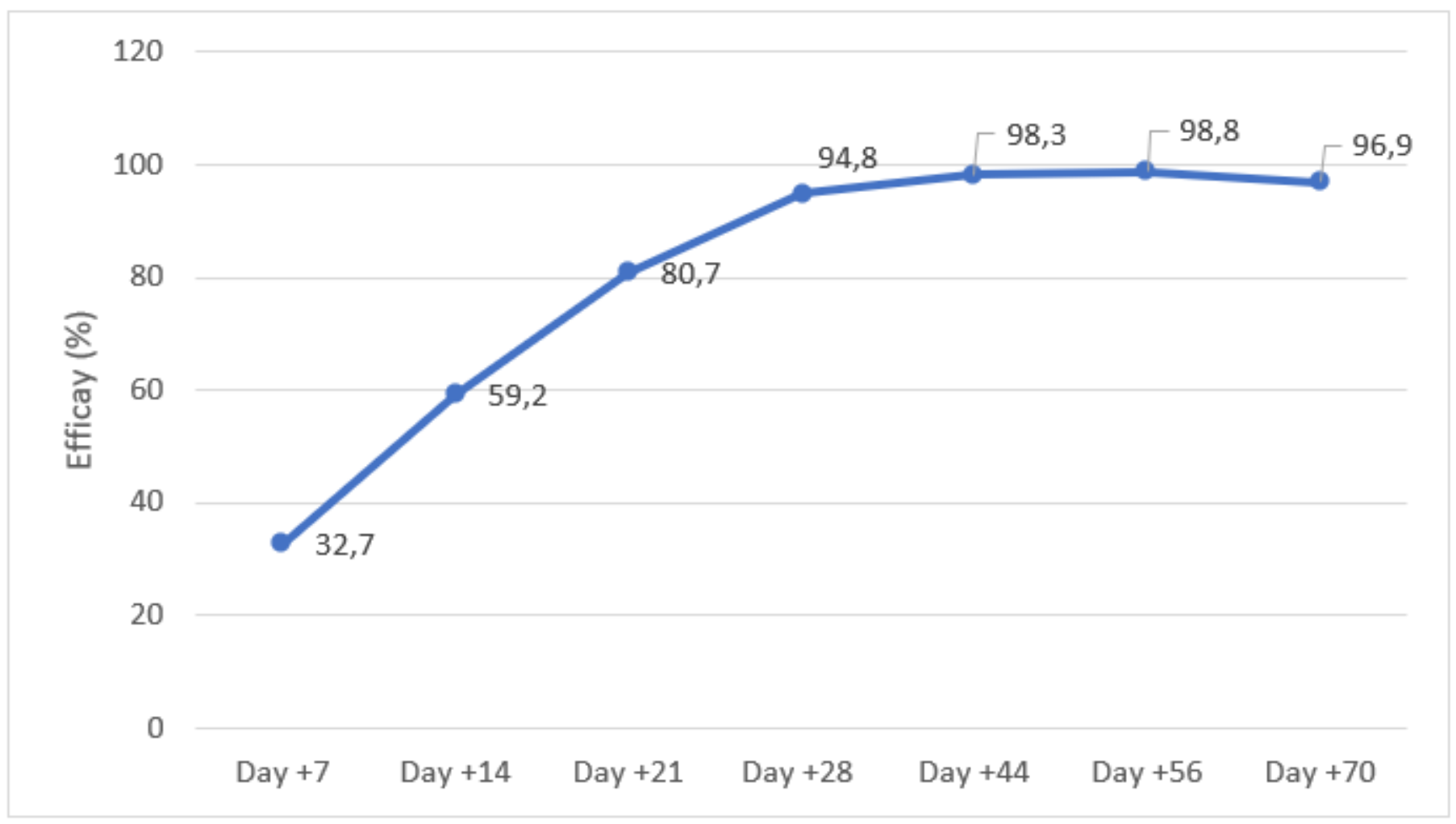

Figure 2. Percentage of efficacy of Exzolt ${ }^{\circledR}$ on $A$. galli based on the number of mites seen in skin scrapings on different evaluation days using the Abbott formula.

Figure 2

Percentage of efficacy of Exzolt ${ }^{\circledR}$ on $A$. galli based on the number of mites seen in skin scrapings on different evaluation days using the Abbott formula. 


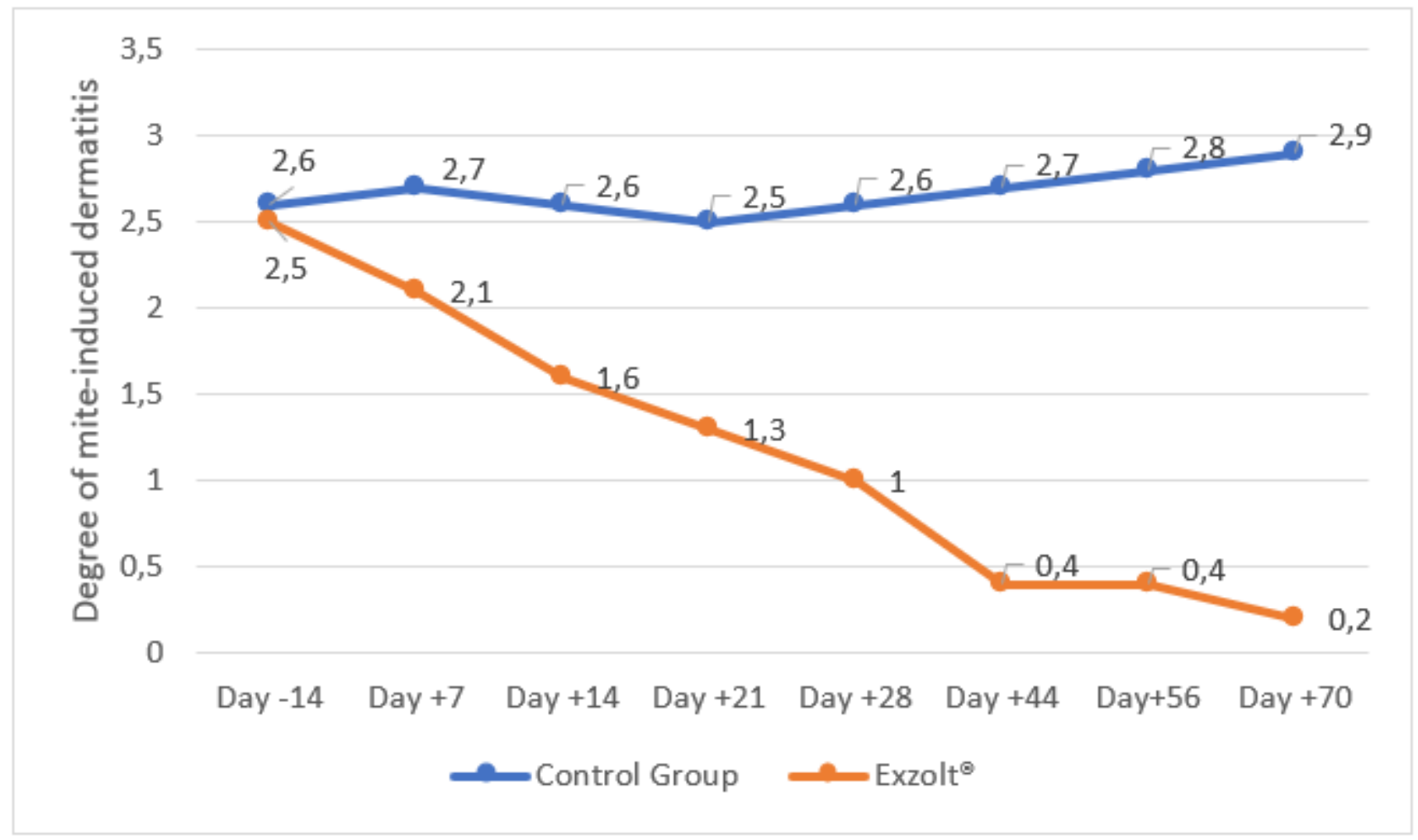

Figure 3. Dermatitis degree of mite-induced by A. galli in laying hens treated and not treated with Exzolt ${ }^{\circledR}$ on different evaluation days.

Figure 3

Dermatitis degree of mite-induced by $A$. galli in laying hens treated and not treated with Exzolt ${ }^{\circledR}$ on different evaluation days. 


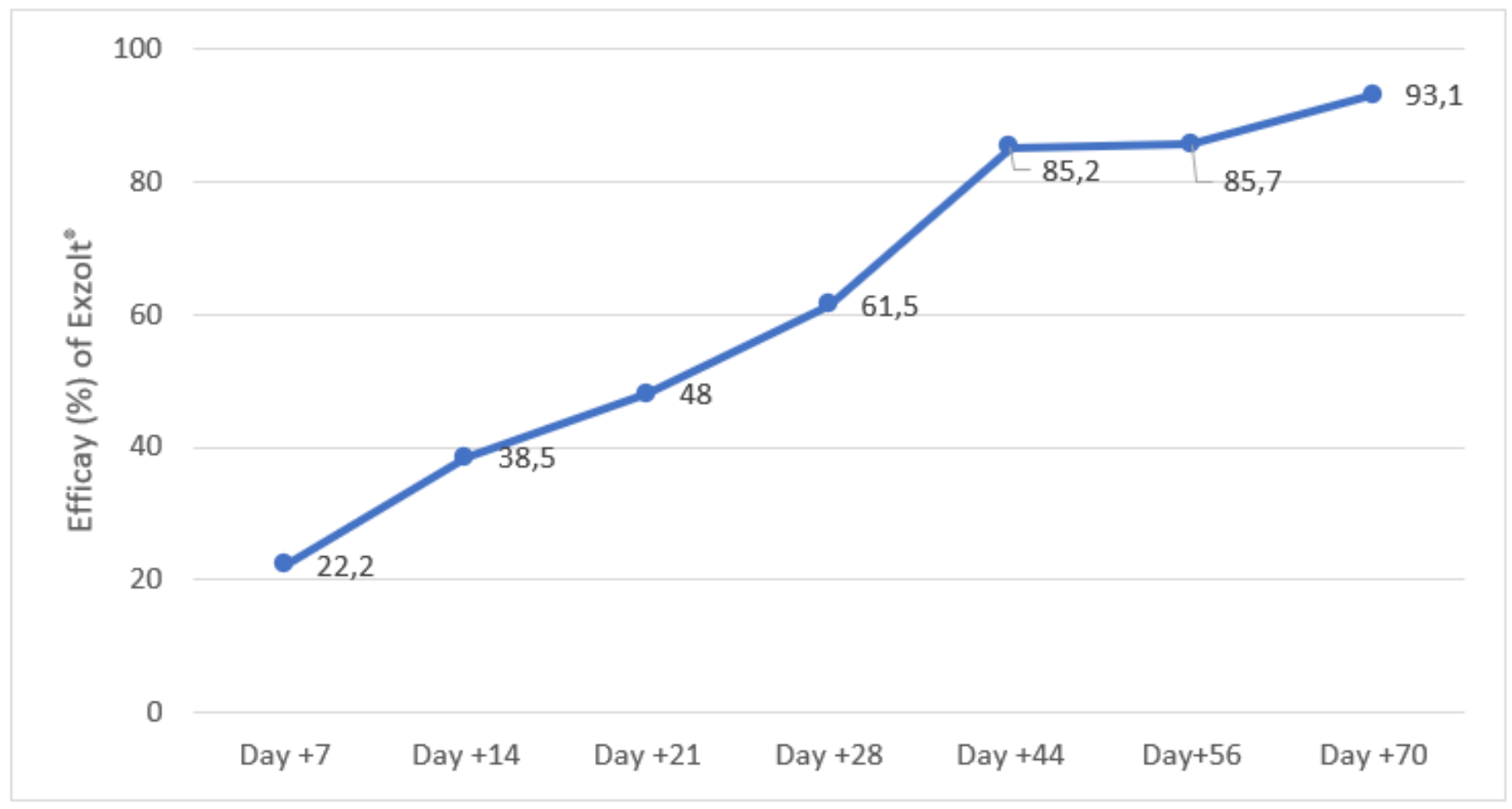

Figure 4. Percentage of efficacy of Exzolt ${ }^{\circledR}$ in reducing the degree of dermatitis caused by A. galli on different evaluation days using the Abbott's formula.

Figure 4

Percentage of efficacy of Exzolt ${ }^{\circledR}$ in reducing the degree of dermatitis caused by $A$. galli on different evaluation days using the Abbott's formula. 